Original Research Article

\title{
Trends of human influenza infection in Chhattisgarh: a retrospective observational study
}

\author{
Raj Sharma, Rupendra K. Bharti*, Sanat Sharma, Mahendra K. Jaiswal
}

Department of Pharmacology, Late BRKM Government Medical College, Dimrapal, Jagdalpur, Chhattisgarh, India

Received: 21 March 2019

Revised: 04 April 2019

Accepted: 03 May 2019

*Correspondence to:

Dr. Rupendra K. Bharti, Email: rbharti000@gmail.com

Copyright: (C) the author(s), publisher and licensee Medip Academy. This is an openaccess article distributed under the terms of the Creative Commons Attribution NonCommercial License, which permits unrestricted noncommercial use, distribution, and reproduction in any medium, provided the original work is properly cited.

\begin{abstract}
Background: Human influenza virus was recognized as a pandemic in 2009 by the World Health Organization (WHO). Since then many newer incidences was recognized in India, but there was no sufficient data from all state of India. This study will provide data from the Chhattisgarh state of India.

Methods: It was a retrospective observational study from December 2015 to November 2017. All patient samples with suspected influenza infection were collected and analysed by Real-time reverse polymerase chain reaction (RTPCR).

Results: 341 patients' sample was collected and analysed; among these samples, $07.9 \%$ of patients have all three serotype of influenza positive. Raipur district has the highest incidence of influenza A followed by Durg and Raigarh district of Chhattisgarh. There was no significant difference between male and female who was affected by the influenza virus.

Conclusions: The incidence of Human influenza virus is lesser in Chhattisgarh as compare to the average states of India and the state capital has a higher rate of sample collection as well as positive influenza infection.
\end{abstract}

Keywords: Chhattisgarh, Influenza, Incidence, Oseltamivir, Pandemic

\section{INTRODUCTION}

Human influenza virus is a pig transmitted infectious disease and it is appeared to be highest mortality causing disease since past decade. ${ }^{1}$ In 2009 , it was recognized as pandemic infectious disease by World health Organization (WHO), which was transmitted via human to human by aerosol. ${ }^{1}$ Influenza was first time recognized as Spanish flu in 1918-1919, which was also pandemic in nature. Illness oftenly present in farmers who had swine in their farms and that was observed by veterinarian J. S. Koen. The isolation of pig derived $\mathrm{H} 1 \mathrm{~N} 1$ virus was first time obtained during 1930 by Shope and Lewis then in 1974 human derived H1N1 virus was isolated, which confirm the hypothesis that pig derived $\mathrm{H} 1 \mathrm{~N} 1$ virus could infect human too. $^{2}$

Human influenza or H1N1 influenza or Swine flu is a respiratory tract disorder comprised of flu like symptoms which include sore throat, rhinorrhoea, fever, chills, vomiting, restlessness, anorexia, headache, arthralgia and diarrhea. In patients with immune deficit, the clinical presentation of swine flu could be worsen and may lead to altered sensorium and respiratory collapse. ${ }^{3}$ Till date five serotype of H1N1 influenza was isolated which are H1N1, H1N2, H2N3, H3N1, and H3N2. Among these only H1N1 causes human infection and rest are seen only in pigs. 
Swine flu is an orthomyxo RNA virus, having two surface antigens (Hemagglutinin type 1) and N1 (Neuraminidase type 1$){ }^{1}$

In India, 27,236 laboratory confirmed cases with 981 deaths were reported during 2009.4,5 The post pandemic period (since 2010) 62,000 laboratory confirmed swine flu with 5000 deaths was reported by the Ministry of Health and Family Welfare and also stated that the incidence was high during monsoon (July to August) and low during winter (December to February). ${ }^{4-8}$ The incidences of H1N1 influenza were keep rising worldwide. In India there was lack in sufficient data of human influenza virus infection from the many states. This study will provide the newly laboratory diagnosed cases of human influenza virus infection in the state of Chhattisgarh.

\section{METHODS}

It was hospital-based retrospective descriptive, recordbased analysis from December 2015 to November 2017. This study was carried out in the Department of Pharmacology, Late BRKM Government Medical College, Dimrapal, Jagdalpur, Chhattisgarh. Patients with the sign and symptoms of influenza viral infection who are falling under category B and C and Confirm case (tested positive for influenza infection) by real-time reverse transcription polymerase chain reaction (RT-PCR) were included in this study. ${ }^{9}$

Patients from category B and C were administered proper therapy for influenza viral infection and samples were sent for confirmation, if the sample was negative, treatment was discontinued. The data related to patients' demographics from the H1N1 visiting screening centers, swine flu outpatient departments and swine flu isolation wards and hospitals from Chhattisgarh were collected. Testing of influenza virus was carried out at microbiology department of Late BRKM Government Medical College, Dimrapal, Jagdalpur.

\section{Collection of samples and confirmation}

Throat or nasal swab samples of suspected cases with influenza-like sign and symptoms were collected in Viral Transport Medium and sent to laboratories maintaining cold-chain. RNA was extracted by Purelink Viral RNA/DNA blood Mini Kit (Carlsbad, CA, USA). RNA of each isolate was tested by separate primer/probe sets for InfA, H1N1 and H1 subtype as per the CDC real-time RTPCR protocol (ABI Step One Plus RT-PCR instrumentApplied Biosystems, USA). ${ }^{10}$ All the data related to demographic characteristics, was analysed using Epi Info v7.2 and Yates corrected chi-square $\left(\chi^{2}\right)$ test. $P$-value $<0.05$ was considered statistically significant.

\section{RESULTS}

Total 341 samples were collected from different hospitals and medical colleges in the state with suspected H1N1 infection. Out of total 341 sample, $54 \%$ patients were male and the mean age was $30.39 \pm 19.2(\mathrm{p}=0.28)$, years-wise comparison depicted in Table 1. Trends of suspected cases of influenza infection between both the gender, higher percentage among female 31 to 40 were observed between 21 to 30 year of age and in males at 0-10 years were the highest (Table 1). Between Dec 2015 to Nov 2017, only $7.9 \%$ patients were found to be positive of all three subtypes of human influenza stain like H1N1, Influenza-A and H1-subtype, while $46.3 \%$ (n-158) patients was found positive for influenza-A, $17.3 \%(n-59)$ for $\mathrm{H} 1 \mathrm{~N} 1,24.9 \%$ (n-85) for H1 subtype infection by RT PCR and all three was positive in $7.9 \%$ (Figure 1). Populated region of Chhattisgarh has higher rate of suspected cases such as Raipur (Capital of Chhattisgarh), and Durg, even the most Trible region of Chhattisgarh (Baster) has comparable higher rate than other district. Maximum number of sample was send from the Raipur district followed by Durg and Raigarh (Figure 2).

Table 1: Age wise distribution of Human Influenza patients $(n=341)$.

\begin{tabular}{|lll|}
\hline Age in decades (years) & Male & Female \\
\hline $0-10$ & $20.7 \%$ & $17.8 \%$ \\
\hline $11-20$ & $07.1 \%$ & $12.1 \%$ \\
\hline $21-30$ & $18 \%$ & $23.3 \%$ \\
\hline $31-40$ & $21.7 \%$ & $16.6 \%$ \\
\hline $41-50$ & $16.3 \%$ & $14 \%$ \\
\hline $51-60$ & $07.1 \%$ & $03.8 \%$ \\
\hline $61-70$ & $07.1 \%$ & $05.7 \%$ \\
\hline$\geq 71$ & 00 & $03.2 \%$ \\
\hline
\end{tabular}

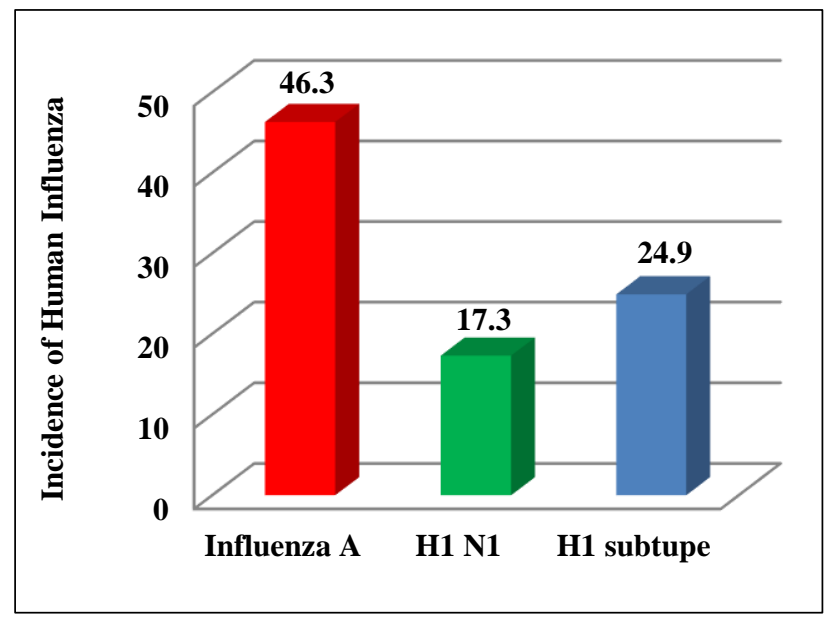

Figure 1: Incidence of newer diagnosed human influenza subtypes from December 2015November 2017.

The $41.8 \%(n=66)$ sample was positive for Influenza A, $39 \%(n-23)$ for H1N1 and 36.5\% (n=31) for H1 subtype infection in district Raipur, whereas in district Durg and Raigarh has $8.9 \%, 11.9 \%, 10.6 \%$ and $2.5 \%, 13.6 \%, 11.8 \%$ sample was positive for Influenza A, H1N1 and H1 subtype, respectively. 


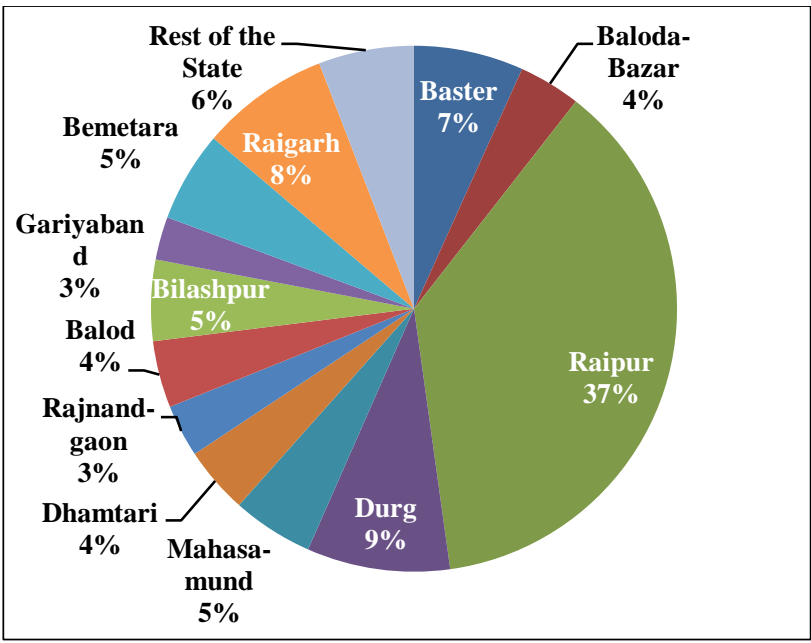

Figure 2: Distribution of percentage of sample sends by the district of Chhattisgarh.

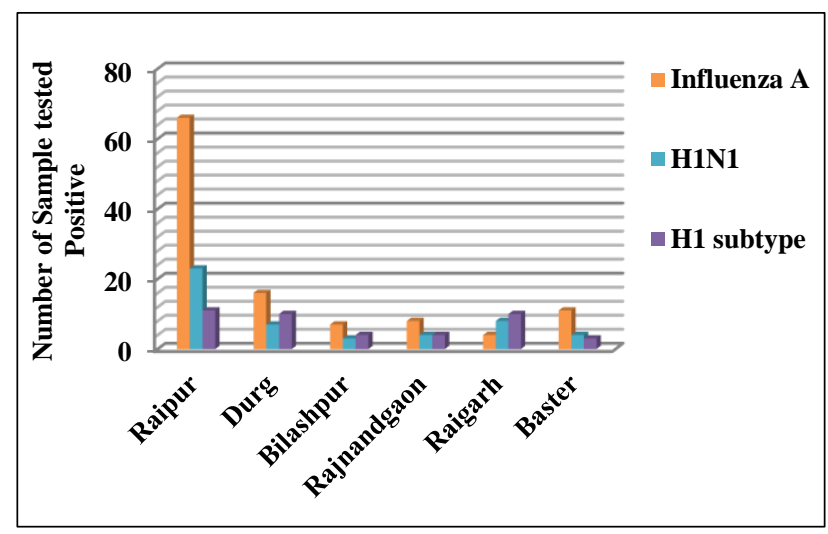

Figure 3: Distribution of Sero-positive influenza subtype in most occurring districts of Chhattisgarh.

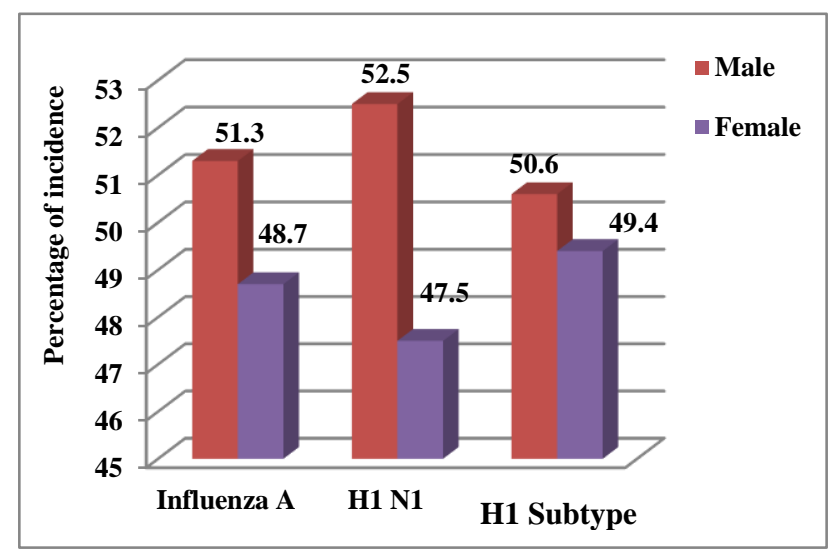

Figure 4: Comparison of positive influenza serotype in between gender.

Raipur has significant number of positive cases of influenza $\mathrm{A}, \mathrm{H} 1 \mathrm{~N} 1$ and $\mathrm{H} 1$ subtype than other district of Chhattisgarh state (Figure 3). There was slightly higher incidence of Influenza A, H1N1, and H1 subtype observed in male patients than female. The mean percentage of Influenza- The positive test for influenza A, H1N1, and H1 subtype was high in males than female patients. A was positive in male patient was $51.3 \%$ as compare to female patient was $48.7 \%$ (OR-0.81), while $52.5 \%$ male patients were positive for $\mathrm{H} 1 \mathrm{~N} 1$ as compare to $47.5 \%$ female patients and $\mathrm{H} 1$ subtype was positive in $50.6 \%$ male patient vs. $49.4 \%$ in female patients (Figure 4).

\section{DISCUSSION}

The incidence of human influenza viral infection in Chhattisgarh is comparable from other state of India. The collections of sample were higher during rainy season as reported in national health profile of India. ${ }^{6}$ From December 2015 to November 2017, a total number of 341 samples were sent to our center, out of which, highest number of sample (37\%) was received from Raipur district followed by Durg (09\%) and Raigarh (08\%) district (figure-1), which was comparable with the incidence of human influenza infection in the district of Rajasthan. ${ }^{11}$ Among these samples $07.9 \%$ was seropositive for all three subtypes of influenza virus such as Influenza-A, H1N1, and H1 Subtype.

The incidence of Influenza-A was 46.3\%, H1N1 (17.3\%), and H1 subtype was 24.9\% (p-NS) from Dec-2015-2017 (Figure 2). Among higher reporting districts of Chhattisgarh, the overall newer case of from Raipur was $41.8 \%$ (p-NS), followed by Durg $(08.9 \%)$ and Baster $(07 \%)$ for Influenza-A subtype. Similarly, H1N1 is also most common seen in Raipur (39\%) followed by Raigarh (13.6\%) then Durg (11.9\%) and, H1 Subtype incidences were also high in Raipur $(36.5 \%)$ then Raigarh $(11.5 \%)$ followed by Durg (10.6\%); (Figure 3). These results signify the higher rate of incidence commonly seen in the state capital as also observed by Malhotra et al. ${ }^{11}$ The mean age of male patients those samples was obtained was $30.39 \pm 19.2$ years as compare to female patients was $30.77 \pm 18.8$ (p-NS). In female, common age group presenting Influenza like symptoms was 21-30 years $(22.3 \%)$, while the common age group in male patients was $31-40$ years $(21.7 \%)$, age-wise distribution is shown in the table-1, and similar distribution was also observed by choudhary et al. ${ }^{12}$

The management of Human Influenza virus is requires isolation of infected person with antiviral therapy and curative management of other complications. Antiviral therapy mainly includes Oseltamivir, Zanamivir, Peramivir, Laninamivir which are neuraminidase inhibitors (NAIs) and Adamantanes such as Amantadine and Rimantadine. ${ }^{13,14}$ Nowadays only NAIs is effective against swine flu due development of resistance against adamantanes. ${ }^{13,14}$ In India, Oseltamivir and Zanamivir is used for the treatment as well as for the prophylaxis of human influenza. ${ }^{11}$ According to WHO, Uncomplicated cases doesn't require antiviral therapy, only patients with suspected symptoms in high risk group were advocated for antiviral therapy. ${ }^{14}$ All patients including pregnant females were included by WHO for antiviral therapy. ${ }^{14}$ 
In adults, oseltamivir is prescribed $75 \mathrm{mg}$ twice daily regimen for 5 days, while Zanamivir is given in a dose of $10 \mathrm{mg}$ twice daily, both drugs can be used as prophylaxis of swine flu in an once daily regimen. ${ }^{11}$ Chemoprophylaxis should be given to the healthcare professionals, Oseltamivir is given once daily for 10 days and may be extended upto 6 weeks depending upon duration of close contact to the patients. ${ }^{1}$ WHO also recommended the vaccine for the healthcare professionals, the response of the vaccine will come after 2-3 weeks after vaccination. There were some limitation in our study; the power of study was low due to less sample size; the mortality was not calculated and we unable to find the commonest sign and symptoms of human influenza virus in Chhattisgarh region of India.

\section{CONCLUSION}

The case of Human influenza virus in Chhattisgarh from the period of December 2015 to November 2017 was only 341 which was less than many states of Chhattisgarh. Higher incidences were observed in the state capital then neighbouring district like Durg and Raigarh. There was no significant difference in between gender affected by human influenza, while Influenza A was more common than $\mathrm{H} 1 \mathrm{~N} 1$ and $\mathrm{H} 1$ subtype among the all received samples. The treatment remains the same for swine flu, which includes neuraminidase inhibitors (NAIs) and Adamantanes.

\section{ACKNOWLEDGEMENTS}

Authors would like to thank Department of Microbiology, Late BRKM GMC Jagdalpur, Chhattisgarh.

\section{Funding: No funding sources}

Conflict of interest: None declared

Ethical approval: The study was approved by the Institutional Ethics Committee

\section{REFERENCES}

1. Rawal G, Yadav S, Kumar R, Sujana R. Swine Flu (H1N1 Influenza A): A concise review. Indian J Immunol Resp Med.2017 April-June;2(2):29-32.

2. Myers KP, Olsen CW, Gray GC. Cases of Swine Influenza in Humans: A Review of the Literature. Clin Infect Dis. 2007 Apr 15;44(8):1084-8.

3. Yadav S, Rawal G. Swine flu-have we learnt any lesson from the past? Pan Afr Med J. 2015 Oct $12 ; 22: 118$
4. Central Bureau of Health Intelligence. National Health Profile of India. 2009. Available at: http://cbhidghs.nic.in/writereaddata/linkimages/8\%20 Health\%20Status\%20Indicators4950277739.pdf .

5. Press Information Bureau, Government of India, Ministry of Health and Family. Preventive measures on swine flu. Available at: http://pib.nic.in/newsite/PrintRelease.aspx?relid=115 710 .

6. Central Bureau of Health Intelligence. National Health Profile of India. 2010. Available at: http://cbhidghs.nic.in/writereaddata/mainlinkFile/File 1012.pdf .

7. Choudhry A1, Singh S, Khare S, Rai A, Rawat DS, Aggarwal RK, et al. Emergence of pandemic 2009 influenza A H1N1, India. Indian J Med Res. 2012;135(4):534-7.

8. Broor S, Krishnan A, Roy DS, Dhakad S, Kaushik S, Mir MA, et al. Dynamic patterns of circulating seasonal and pandemic $\mathrm{A}(\mathrm{H} 1 \mathrm{~N} 1)$ pdm09 influenza viruses from 2007-2010 in and around Delhi, India. PLoS One. 2012;7(1):e29129.

9. Guidelines on Categorization of Influenza a H1N1 Cases during Screening for Home Isolation, Testing Treatment, and Hospitalization. Available at: http://www.mohfw.nic.in/WriteReadData/1892s/8044 56402Categorisation.pdf.

10. CDC Protocol of Real Time RTPCR for Influenza A (H1N1). Available at: http://www.who.int/csr/resources/publications/swinef lu/CDCRealtimeRTPCR_SwineH1Assay2009_20090 430.pdf

11. Malhotra B, Singh R, Sharma P et al. Epidemiological \& clinical profile of influenza A (H1N1) 2009 virus infections during 2015 epidemic in Rajasthan. Indian J Med Res 2016;144(6):918-23.

12. Choudhary SR, Momin MH, Chauhan NT. Profile of influenza a $(\mathrm{H} 1 \mathrm{~N} 1)$ positive patients of surat district. Int J Contemporary Med Res. 2017;4(2):504-506.

13. Singh V, Sood M. Swine Flu - A comprehensive view. Int J Adv Res Technol. 2012;1(2):1-5.

14. Mukherjee S, Sen S, Nakate PC, Moitra S. Management of swine flu (H1N1 Flu) outbreak and its treatment guidelines. Community Acquir Infect. 2015;2(3):71-8.

Cite this article as: Sharma R, Bharti RK, Sharma $\mathrm{S}$, Jaiswal MK. Trends of human influenza infection in Chhattisgarh: a retrospective observational study. Int J Basic Clin Pharmacol 2019;8:1288-91. 